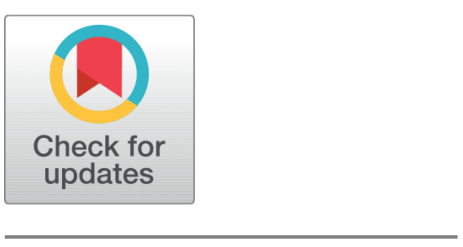

OPEN ACCESS

Received: 05.10 .2020

Accepted: 20.12 .2020

Published: 23.02 .2021

Citation: Mustahsan M, Younas HM, Salamat N, Touqeer M, Abbas M (2021) Modeling the thermo physical behavior of metallic porous fin on varying convective loads. Indian Journal of Science and Technology 14(6): 558-572. https://doi.org/ 10.17485/IJST/v14i6.1761

* Corresponding author.

muhammad.mustahsan@iub.edu.pk

Funding: None

Competing Interests: None

Copyright: (c) 2021 Mustahsan et al. This is an open access article distributed under the terms of the Creative Commons Attribution License, which permits unrestricted use, distribution, and reproduction in any medium, provided the original author and source are credited.

Published By Indian Society for Education and Environment (iSee)

ISSN

Print: 0974-6846

Electronic: 0974-5645

\section{Modeling the thermo physical behavior of metallic porous fin on varying convective loads}

\author{
Muhammad Mustahsan ${ }^{1 *}$, Hafiz Muhammad Younas ${ }^{1}$, Nadeem Salamat $^{2}$, \\ Muhammad Touqeer ${ }^{3}$, Muntazim Abbas ${ }^{2}$ \\ 1 Department of Mathematics, The Islamia University of Bahawalpur, Pakistan \\ 2 Department of Mathematics, Khawaja Fareed UEIT, Rahim Yar Khan, Pakistan \\ 3 Basic Sciences Department, University of Engineering and Technology, Taxila, Pakistan
}

\section{Abstract}

Background/ Objectives: Porous-permeable structured fins are the principal operational mechanism for enhancing the percentage of heat evolved and dissipated because of their many thermo physical characteristics. Study of thermal gradients on the basis of convective loads in porous fins is important in many engineering fields. Methods: In the present fractional investigation, well-established optimal homotopy asymptotic method (OHAM) has been applied on thermal system expressed in nonlinear fractional order of ordinary differential equations for Darcy's approach for porous-structured fin. Here parameters related to porosity, permeability and convection have been deliberated. In order to study the thermal solicitations, the thermal analysis with insulated tip of copper based alloy is studied. Findings: It is found that porosity of system is influencing more than other factors. Novelty: This study demonstrates the efficiency of OHAM as well.

Keywords: Porous; thermal; Optimal Homotopy Asymptotic Method (OHAM); darcy

\section{Introduction}

The study of thermo-physical properties in convective stream through porous permeable medium is highly commendable in numerous engineering problems. Porous permeable metallic and ceramic materials have a lot of industrials and bio medical situations and no doubt could become modern materials with their vast applications in fields. Several mathematical and investigational studies were carried out to deliver a profounder consideration of the transportation instrument for the temperature transferal confidential the porous permeable medium. Porous permeable media has widespread solicitations like catalytic bed reactors, improving dehydrating effectiveness, sieving, isolation, and dealing petroleum recovery. The thermionic conductive porous permeable substances are used to augment forced convective heat transfer problems in several technological problems like reactor designing, thermal components like exchangers, and parabolic shape solar plates heaters ${ }^{(1-5)}$. The rapid and fast expansion of electronic machinery has developed more noticeable modifications 
in several manufacturing, business, and ecological problems. This expansion did not happen without an accompanied progress in heat dissipation (cooling) approaches. Augmentation of natural convection has been and will continue to be fundamental in refining the demonstration of the heat dissipation apparatuses of integrated circuit based technology confined.

Fin or stretched surface is a nice operational component to augment heat transfer from the heated regions and surfaces. It has been extensively functional in atmospheric heat conditioning, automotive, heat transfer equipment, etc. The main objectives of these investigations are dropping the dimensional/geometrical perspectives and material price of fin-based system ${ }^{(3-8)}$. The enhancement of heat dissipation capabilities in extended surfaces or fins have been given preferences in research and development that has guided to utilization on the use of porous fins. The enhancement of heat dissipation capabilities in extended surfaces have been a theme of enthusiastic prominence that has directed to widespread investigation on the use of porous finned structures (PFS). Two factors that are most prominent in system are; one is permeability i.e. inter connectivity of pores and scale of pores in PFS and second is convective load. Ghasemi et al. ${ }^{(7,8)}$ had a preliminary investigation on heat transfer in fin. They studied heat transfer of fin as compared to the porous fin escalations heat transfer geometrical benefits for a definite area and shrinkages the material mass by eliminating the solid mass with holes and cavities. It is important to narrate that Kiwan and Al-Nimr ${ }^{(9)}$ initially announced perception of employing PFS to augment heat dissipation. Also Kiwan ${ }^{(10)}$ familiarized the Darcy approach to designate the solid-gas/air interfaces in the PFS. Khaled ${ }^{(11)}$ studied heat dissipation in the quadrangular permeable fin and determined that the PFS improved heat dissipation rate. Kiwan and Zeitoun ${ }^{(12)}$ established that the cylinder-shaped permeable fin augmented thermionic transitions. Ghasemi et al. ${ }^{(13)}$ associated heat transfer presentations of solid permeable fins with 60 thermal controlled heat transfers. Kiwan ${ }^{(14)}$ assessed thermionic radiation possessions in heat dissipation in (PFS). E. Cuce and P. M. Cuce ${ }^{(15)}$ efficaciously used HPM to evaluate fin efficacy and performance analysis of the quadrangular permeable fin. Numerical approach has been used by Ma et al. ${ }^{(16)}$ to investigate thermal capacity of the convective radiative permeable fin. Moradi et al. ${ }^{(17)}$ employed a HPM modelled convective capacity and radiation thermal dissipation in the moveable porous-permeable fin. Bhanja et al. ${ }^{(18)}$ formulated and followed analytical model based approach to attain fin performance and maximum design geometrical values and constraints of a movable porous-structured-fin uncovered in convective-radiative environment. Some other scientists like $\mathrm{Das}^{(19)}$ approved the inverse results of convection-radiation base approach for cylinder-shaped porous-permeable fins. The factors of permeability along with porosity and internal heat evolved in the system are linked to many applications. The many physio-thermal characteristics of porous-structures in metals and ceramics have been investigated by the features of the connected solid part and the fluids encompassed in the porous membranes and structures ${ }^{(20-29)}$. Mohammad Hemmat Esfe et al. ${ }^{(30)}$ provide a comprehensive review on convective heat transfer of nano fluids in porous media. Liaqat Ali et al. ${ }^{(31)}$ studied thin-film flow of magneto hydrodynamic (MHD) fluid in the presence of thermal conductivity and variable viscosity over a porous steady stretching surface with a magnetic field and radioactive heat fluctuation. Partner L. Ndlovu ${ }^{(32)}$ the variation of temperature distribution and fin efficiency in a porous moving fin of rectangular profile is studied. Zahirhah et al. ${ }^{(33-42)}$ study the inventive conception of the electrical Magneto hydrodynamics (MHD) rotational flow of Single and Multi-Walled Carbon nanotubes (SWCNTs/MWCNTs) base on the fluids (water, engine oil, ethylene glycol and kerosene oil). Darcy-Forchheimer ${ }^{(2)}$ three-dimensional micropolar rotational nanofluid flow of single wall and multiwall carbon nanotubes base on the fluids (water, engine oil, ethylene glycol and kerosene oil). Hall Effect on Couple Stress 3D Nanofluid Flow over an Exponentially Stretched Surface with Cattaneo Christov Heat Flux Mode. ${ }^{(3)}$ Radiative flow of magneto hydrodynamics single-walled carbon nanotube over a convectively heated stretchable rotating disk with velocity slip effect. ${ }^{(5)}$ Darcy Forchheimer nanofluid thin film flow of SWCNTs and heat transfer analysis over an unsteady stretching sheet. ${ }^{(6)}$ Impact of Nonlinear Thermal Radiation on MHD Nanofluid Thin Film Flow over a Horizontally Rotating Disk. ${ }^{(7)}$ Radiative heat and mass transfer analysis of micropolar nanofluid flow of Casson fluid between two rotating parallel plates with effects of Hall current. ${ }^{(8)}$ Uniform magnetic force impact on water based nanofluid thermal behavior in a porous enclosure with ellipse shaped obstacle. ${ }^{(9)}$ Application of Electric Field for Augmentation of Ferrofluid Heat Transfer in an Enclosure with Double Moving Walls. ${ }^{(10)}$ The electrical MHD and hall current impact on micropolar nanofluid flow between rotating parallel plates.

In the fractional calculus, the concept of non-integral order differentiation and integration has been used. Fractional calculus is the generalization of the classical calculus. From the last many years, many mathematicians, researchers and scientists have observed that the role of non-integer operators is very important in expressing the properties of physical phenomena. Many procedures and apparatus have been proficiently expounded by fractional differentiation and integrals. Additional relative study has been done between classical models and fractional models ${ }^{(20-25)}$. OHAM technique is rapidly convergent as compared to other techniques. The reliability and effectiveness of OHAM has been shown in literature with several applications in different fields of sciences and engineering.

The paper is categorized in four sections. In Section 2; the governing equation based upon the heat transfer equation is formulated. In Section 3; Computational remarks for solution based on OHAM are given. Some numerical examples are 
considered in section 4 . The findings are tabulated and graphical results are shown in this section.

\section{Governing Equation}

A quadrangular fin contour has chosen and deliberated in this work, for investigating the behavior of convective effects, as shown in Figure 1. The convection of system is written in term of differential equation. The geometrical measurements of the fin are given as: its length is described as " $\mathrm{L}$ ", width is described as "w" and thickness is described as " $\mathrm{t}$ ". The cross segment area of the fin is not variable rather than fixed. This fin has particular porosity to permit the stream of penetrate through it. The subsequent assumptions are taken to elucidate the objectives.

Energy balance can be written as:

The system is translated in Darcy's porous-structure approach with total energy balance of the system is presented as

$$
q(y)-q(y+\Delta y)+q^{*} A \Delta(y)=m^{*} C(p)\left[\tau-\tau_{\infty}\right]+h(p) \Delta y\left[\tau-\tau_{\infty}\right]
$$

Whereas, the mass-flow rate of the convective-fluid streaming PFS is given as

$$
m^{*}=\rho \cdot v \cdot w(y) \triangle(y) \text {. }
$$

And velocity as flow-steam is given as :

$$
\theta_{w}=\frac{g k \beta\left(\tau-\tau_{\infty}\right)}{\theta}
$$

In this system, it is presumed that heat energy generated in the fin varies with temperature. Here the concept of energy balance is used for steady state condition,

$$
\begin{gathered}
\frac{d^{2} \theta}{d y^{2}}-S_{h} \theta^{2}(y)-m^{2} \theta(y)+m^{2} G(1+\varepsilon \theta)=0 \\
\text { Where } \theta=\frac{\left(\tau-\tau_{\infty}\right)}{\left(\tau_{b}-t_{\infty}\right)} \text { and } Y=\frac{y}{L}
\end{gathered}
$$

Porous parameter, $S_{k}=\frac{D_{a} R_{a}}{k}\left(\frac{L}{t}\right)$ and Convection parameter, $m=\left(\frac{h_{p}}{K, A}\right)^{\frac{1}{2}}$ Here, $S_{h}$ is a parameter related to porosity that defines the permeability of the porous structure as well as buoyancy effect. If the value of $S_{h}$ is higher, then it specifies greater interconnected-porousness of the PSF or greater buoyantic forces. Here, $\mathrm{m}$ is a convective parameter that designates the consequence of convection from the surface of the fin. The conditions to be considered for the work are for finite length fin with insulated tip $\theta(0)=1,\left.\frac{d \theta}{d y}\right|_{y=1}=0$. In order to solve non-linear problems, the idea of homotopy has been combined with perturbation method. In his investigation, Lio ${ }^{(9)}$ did the fundamental work by using homotopy analysis method. A novel technique, which is known as OHAM, was created by Marinca et.al. ${ }^{(29)}$. The benefit of OHAM is that it establishes its convergence criteria similar to HAM but more pliable. R. Kumar ${ }^{(43)}$ provide the three-dimensional (3D) analysis for Cassonnanofluid and Carreau-nanofluid flows due to a flat body in a magneto hydrodynamic (MHD). Nawaz et al. ${ }^{(44)}$ use the Optimal Homotopy Asymptotic Method for solution of a coupled system of nonlinear partial differential equations. In various research papers, S. Iqbal et al. ${ }^{(45-49)}$, have proved usefulness generalization and trust of this method, and achieved trust worthy solutions, and presented important applications in science and engineering. Concept of OHAM has articulated in this paper. It provides logical, trust worthy solution to linear, non-linear, time dependent, time fractional and space fractional differential equations \& PDEs. 


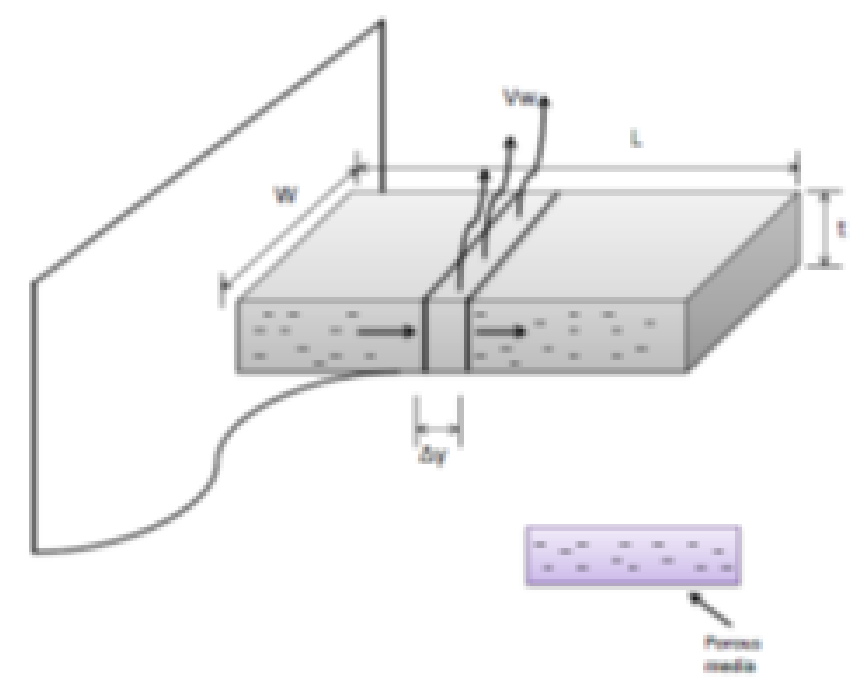

Fig 1. Sketch of porous fin structure

\subsection{Basic definitions of fractional calculus}

In this section, we give some basic definitions of real valued functions.

Definition: A function of real value $f(\mathrm{t}), t>0$, assumed to be in space $c_{\mu}, \mu \in R$. If there exists, $p>\mu$ is a real number such that $f(t)=t^{p} f_{1}(t)$, Where $f_{1}(t) \in c(0, \infty)$, assumed to be in space $c_{\mu}^{m}$ if and only if $f^{m} \in c_{\mu}, m \in N$.

Definition: Riemann-Liouville sense integral operator of a function $f \in c_{\mu}$, of fractional order $\alpha>0, \mu \geq-1$ is defined as

$$
{ }^{R L} D_{a, t}^{-\alpha} f(t)=\frac{1}{\Gamma(\alpha)} \int_{a}^{t}(t-\mu)^{\alpha-1} f(\mu) d \mu, t>0, a>0, k-1<\alpha<k, k \in Z^{+}
$$

Definition Riemann-Liouville sense derivative operator of a function $f(t)$ of fractional order $\alpha>0$ is defined as

$$
{ }^{R L} D_{a, t}^{\alpha} f(t)=\frac{1}{\Gamma(n-\alpha)} \frac{d^{k}}{d t^{k}} \int_{a}^{t}(t-\mu)^{k-\alpha-1} f(\mu) d \mu, \mathrm{a}>0, t>0, k-1<\alpha<k, k \in Z^{+}
$$

Caputo sense derivative operator of a function $f(y)$ of fractional order $\alpha>0$ is defined as

$$
{ }^{C} D_{a, t}^{\alpha} f(t)=\frac{1}{\Gamma(n-\alpha)} \int_{a}^{t}(t-\mu)^{k-\alpha-1} f^{k}(\mu) d \mu, \alpha>0, t>0, k-1<\alpha<k, k \in Z^{+}
$$

If $j-1<\alpha<j$, and $f \in c_{\mu}^{m}, \mu \geq-1$, then

$$
{ }^{R L} D_{a, t}^{-\alpha}\left({ }^{C} D_{a, t}^{\alpha} f(t)\right)=f(t)-\sum_{i=0}^{j-1} f^{i}(a) \frac{(t-a)^{j}}{\Gamma(i+1)}, \mathrm{t}>0
$$

OHAM Scheme for fractional order heat-transfer differential equation.

According to the OHAM algorithm ${ }^{(16,17)}$. We shall extend this scheme for fractional heat-transfer differential equation $\{\mathrm{FPDE}\}$ in the following steps.

Step-1:

Compose the fractional order heat-transfer governing equation as

$$
J(\theta(y))-h(y)=0, y \in \Omega
$$

Where $\Omega$ is domain. Now equation (10) is decomposed in to $J(\theta)=Q(\theta)+T(\theta)$ 
Where $Q$ is a linear part and $T$ is a non-linear part but it is worth noting that this is not necessary. Here we can take liberty about choice of $Q$.

Step-2:

Make an optimal homotopy for time fractional order partial differential equation, $\Psi(y, p): \Omega \times[0,1] \rightarrow R$ which satisfies:

$$
(1-p)\{Q(\Psi(y ; p))+h(y)\}-H(y, p)\{J(\Psi(y ; p))+h(y)\}=0
$$

Where $P \in[0,1]$ is embedded factor, for $p \neq 0, H(y, p)$ is actually nonzero auxiliary function and $H(0)=0$ when $\mathrm{P}$ increases in the interval $[0,1]$, the solution $\Psi(y, p)$ certifies a rapidly convergence to the exact solution.

$$
H(y, p)=p k_{1}\left(y, c_{i}\right)+p^{2} k_{2}\left(y, c_{i}\right)+p^{3} k_{3}\left(y, c_{i}\right)+\ldots+p^{m} k_{m}\left(y, c_{i}\right)
$$

Where $c_{i} ; i=1,2,3, \ldots m$ is auxiliary control parameter of convergence, and $k_{i}(y), i=1,2,3, \ldots m$, may be function $y$. The selections of $k_{m}\left(y, c_{i}\right)$ may be polynomial, exponential etc. The selection of functions is very important, because the rate of convergence of the solution really depends on the functions.

Step-3:

Extend $\Psi\left(y, ; p, k_{i}\right)$ in Taylor's series about $\mathrm{p}$, to develop an approximate result as

$$
\begin{aligned}
& \Psi\left(y ; p, k_{i}\right)=\theta_{0}(y)+\sum_{k=1}^{m} \theta_{k}\left(y ; k_{i}\right) p^{k} \\
& i=1,2, \ldots, m
\end{aligned}
$$

It has been cleared that the rate of convergence of the (13) depends upon auxiliary constants $k_{i}$.

If it is convergent at $\mathrm{p}=1$, one has

$$
\theta^{\sim}\left(y ; k_{i}\right)=\theta_{0}(y ; k)+\sum_{k \geq 1}^{m} \theta_{k}\left(y ; k_{i}\right), i=1,2, \ldots, m
$$

Step-4:

Substituting eq. (14) in eq. (10) yields the following expression for residual:

$$
R\left(y ; k_{i}\right)=Q\left(\theta\left(y ; k_{i}\right)\right)+T(\theta(\mathrm{y}, k))-h(y)
$$

(i) Construct the $\left(c_{i}\right)$; Where

$$
\phi\left(c_{i}\right)=\int_{0}^{t} \int_{\Omega} R^{2}\left(y ; k_{i}\right) d y
$$

$\mathrm{R}$ is a residual of the problem Heat Transfer Equation

(ii) Auxiliary constants $c_{i}$ can be calculated as follows

$$
\frac{\partial \phi}{\partial c_{1}}=\frac{\partial \phi}{\partial c_{2}}=\ldots=\frac{\partial \phi}{\partial c_{m}}=0
$$

If $R\left(\mathrm{y} ; k_{i}\right)=0$, then $\theta\left(y ; k_{i}\right)$ will be the exact solution. Normally it does not happen, likely in non-linear problems.

Step-5:

The use of auxiliary constants in equation (14), we can get the rapidly convergent approximate solutions.

\section{Applications of fractional order heat transfer model}

In this section, consider the Fractional Order Heat Transfer Problem for $\{\mathrm{OHAM}\}$ algorithm. This represents the accuracy, validity and effectiveness of the extended OHAM algorithm.

Let us consider the following heat transfer fractional order model from equation (4)

$$
\theta^{\alpha}(y)-s \theta^{2}-m^{2} \theta+m^{2} G(1+\in \theta)=0, y \in[0,1], 1<\alpha \leq 2
$$

We can make an optimal homotopy in above equation with OHAM algorithm as

$$
\left[(1-p)\left(\theta^{\alpha}(y)\right)-\left(p c_{1}+p^{2} c_{2}+p^{3} c_{3}\right)\left(\theta^{\alpha}(y)-s \theta^{2}-m^{2} \theta+m^{2} G(1+\in \theta)\right)\right]=0
$$


In the following $p^{0}, p^{1}, p^{2}$ and $p^{3}$ are zeroth-order, first-order, second-order and third-order problems.

$$
\begin{gathered}
p^{0}: \theta_{0}^{\alpha}(y)=0 \\
p^{1}:-G m^{2} c_{1}+m^{2} c_{1} \theta_{0}(y)-G m^{2} \in c_{1} \theta_{0}(y)+s c_{1}\left(\theta_{0}(y)\right)^{2}-\theta_{0}^{\alpha}(y)-c_{1} \theta_{0}^{\alpha}(y)+\theta_{1}^{\alpha}(y)=0 \\
p^{2}:-G m^{2} c_{2}+m^{2} c_{2} \theta_{0}(y)-G m^{2} \in c_{2} \theta_{0}(y)+s c_{2}\left(\theta_{0}(y)\right)^{2}+m^{2} c_{1} \theta_{1}(y)-G m^{2} \in c_{1} \theta_{1}(y) \\
+2 s c_{1} \theta_{0}(y) \theta_{1}(y)-c_{2} \theta_{0}^{\alpha}(y)-\theta_{1}^{\alpha}(y)-c_{1} \theta_{1}^{\alpha}(y)+\theta_{2}^{\alpha}(y)=0 \\
p^{3}:-G m^{2} c_{3}+m^{2} c_{3} \theta_{0}(y)-G m^{2} \in c_{3} \theta_{0}(y)+s c_{3}\left(\theta_{0}(y)\right)^{2}+m^{2} c_{2} \theta_{1}(y)-G m^{2} \in c_{2} \theta_{1}(y) \\
+2 s c_{2} \theta_{0}(y) \theta_{1}(y)+s c_{1}\left(\theta_{1}(y)\right)^{2}+m^{2} c_{1} \theta_{2}(y)-G m^{2} \in c_{1} \theta_{2}(y)+2 s c_{1} \theta_{0}(y) \\
\theta_{2}(y)-c_{3} \theta_{0}^{\alpha}(y)-c_{2} \theta_{1}^{\alpha}(y)-\theta_{2}^{\alpha}(y)-c_{1} \theta_{2}^{\alpha}(y)+\theta_{3}^{\alpha}(y)=0
\end{gathered}
$$

In the following $\theta_{0}, \theta_{1}$ and $\theta_{2}$ are zeroth-order, first-order and third-order solutions, using these three solutions in equation 14, we get $\theta$ solution.

$$
\begin{gathered}
\theta_{0}=1 \\
\theta_{1}=\frac{y^{\alpha}\left(-s+m^{2}(-1+G+G \in)\right) c_{1}}{\Gamma(1+\alpha)} \\
\theta_{2}=y^{\alpha}\left(-s+m^{2}(-1+G+G \in)\right)\left(\frac{y^{\alpha}\left(-2 s+m^{2}(-1+G \in)\right) c_{1}^{2}}{\Gamma(1+2 \alpha)}+\frac{c_{1}+c_{1}^{2}+c_{2}}{\Gamma(1+\alpha)}\right) \\
\theta=1+\frac{y^{\alpha}\left(-s+m^{2}(-1+G+G \in)\right) c_{1}}{\Gamma(1+\alpha)} \\
\theta_{a}=-\left(s-m^{2}(-1+G+G \in)\right) c_{1}
\end{gathered}
$$

Residual of equation 17 , can be written as

$$
R=\theta_{a}-s \theta^{2}-m^{2} \theta+m^{2} G(1+\in \theta)
$$

For the solution of auxiliary constant $c_{1}$, the least squares method involves that setting

$$
\frac{\partial J}{\partial c_{1}}=0
$$

Provides the values of $c_{1}$ constant, where

$$
J=\int_{0}^{1} \mathrm{R}^{2} \mathrm{dy}
$$

And here after substitution in (27) and simplification, we get $R$

$$
R=-s+m^{2}(-1+G+G \in)+\left(s-m^{2}(-1+G+G \in)\right)\left(-1+\frac{y^{\alpha}\left(m^{2}+2 s-G m^{2} \in\right)}{\Gamma(1+\alpha)}-\frac{s y^{2 \alpha}\left(s-m^{2}(-1+G+G \in)\right) c_{1}}{\Gamma(1+\alpha)^{2}}\right) c_{1}
$$




\section{Results and Discussions}

The OHAM algorithm presented in sec-3 for time fractional order heat-transfer equation and explanation of the formulation in the examples of sec-4, provides extremely valid results for the problems without any spatial discretization. While applying $\{\mathrm{OHAM}\}$, there is no need to compute higher order solutions. Values of materials properties are taken from ${ }^{(33)}$ as

$D_{a}=0.0003 ; L / t=10, R_{a}=10000, K_{r}=954, \varepsilon=0.5, K_{s}=411$.

In the following Tables $1,3,5,7$ and 9 represents the different values of auxiliary constant $c_{1}$. Tables 2, 4, 6, 8 and 10 represents the approximate results, which are also represents the validity and accuracy of the method.

\section{Case-1 For different Values of $\alpha$}

In this case, fractional thermal analysis for variations in $\alpha$ is given.

For 1.8;

$$
\begin{gathered}
J=9.02161296-5.048478666599252 c_{1}+23.68925641097978 c_{1}^{2} \\
-19.813543640032794 c_{1}^{3}+11.308170664541874 c_{1}^{4}
\end{gathered}
$$

After using the equation (28), we acquire the following $c_{1}$ values

$$
\left\{\begin{array}{l}
\left\{c_{1} \rightarrow 0.12403630242308192\right\},\left\{c_{1} \rightarrow 0.5950358573833419-0.7387557443303318 \mathrm{i}\right\} \\
\left\{c_{1} \rightarrow 0.5950358573833419+0.7387557443303318 \mathrm{i}\right\}
\end{array}\right\}
$$

Selecting the real value of $c_{1}$, i.e., $c_{1}=0.12403630242308192$; similarly other real values of $c_{1}$ with different values of $\alpha$ are presented in the Table 1.

Table 1. First order auxiliary constant of Case-1 for different values of $\alpha$

\begin{tabular}{|c|c|c|c|c|}
\hline $\mathrm{X}$ & $\alpha=1.2$ & $\alpha=1.4$ & $\alpha=1.6$ & $\alpha=1.8$ \\
\hline 0 & 1 & 1 & 1 & 1 \\
\hline 0.1 & 0.9480000443327921 & 0.9744596122996947 & 0.9890112905216663 & 0.9964779968864528 \\
\hline 0.2 & 0.8805354729303191 & 0.9325985127704808 & 0.9666884619982394 & 0.9877356728222831 \\
\hline 0.3 & 0.8056661391001716 & 0.8810957871735966 & 0.9362704724185412 & 0.9745546754809605 \\
\hline 0.4 & 0.7255425885491176 & 0.8221264088055824 & 0.8990182999895816 & 0.9572931322679625 \\
\hline 0.5 & 0.6412705938564254 & 0.756899701789916 & 0.8556892451032061 & 0.9361830941972867 \\
\hline 0.6 & 0.5535380273282889 & 0.6862099011026739 & 0.8068081985378031 & 0.9113942336267902 \\
\hline 0.7 & 0.4628190271555963 & 0.6106279788060684 & 0.7527686413036655 & 0.8830591604082674 \\
\hline 0.8 & 0.3694624458992538 & 0.5305887786027642 & 0.6938807287596512 & 0.8512860489570467 \\
\hline 0.9 & 0.2737368905864366 & 0.4464370708163681 & 0.6303976646426208 & 0.8161658241048135 \\
\hline 1 & 0.1758562425476251 & 0.35845446680108883 & 0.5625315961546157 & 0.7777766268225289 \\
\hline
\end{tabular}

\begin{tabular}{ll}
\hline$\alpha$ & $c_{1}$ with $m=0.1, s=3, G=0.4, \in=0.6$ \\
\hline 1.2 & 0.30231843281528586 \\
1.4 & 0.2653176835941392 \\
1.6 & 0.20822199156438242 \\
1.8 & 0.12403630242308192 \\
\hline
\end{tabular}

Table 2. Results of Case-1 for different values of $\alpha$ 


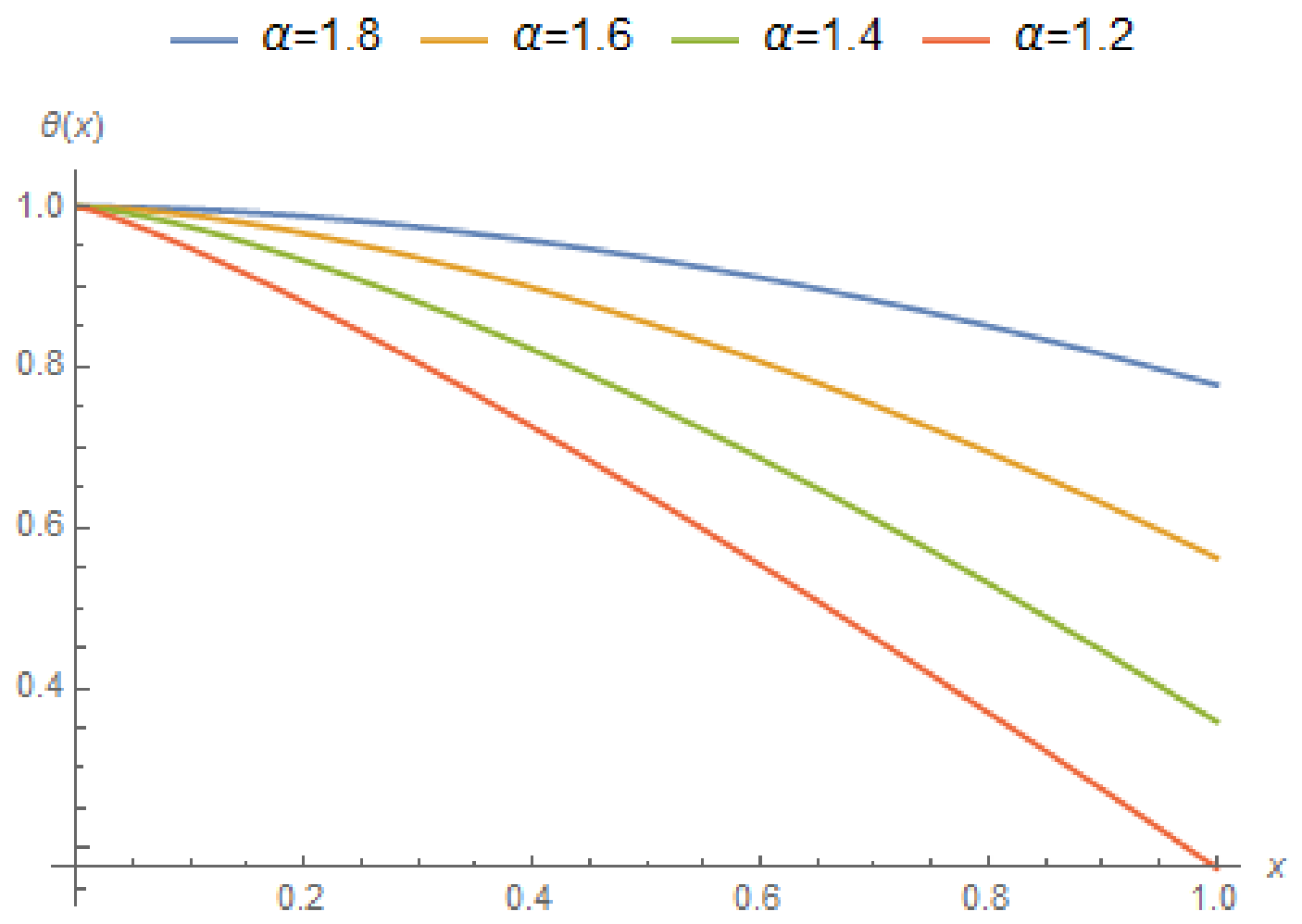

Fig 2. Temperature gradient for 2D Solutions of Case-1 with different values of $\alpha$

\section{Case-2 For different Values of $\epsilon$}

In this case, fractional thermal analysis for variations in $\in$ is given.

For $\in=0.8$

$$
\begin{aligned}
J= & 16.202235039999998-55.217410732990416 c_{1}+197.13144762161022 c_{1}^{2} \\
& -333.0110077388577 c_{1}^{3}+267.30228718236975 c_{1}^{4}
\end{aligned}
$$

After using the equation (28) we acquire the following $c_{1}$ values

$$
\left\{\begin{array}{l}
\left\{c_{1} \rightarrow 0.2762700280567808\right\},\left\{c_{1} \rightarrow 0.32904814859405135-0.28045957195433746 \mathrm{i}\right\} \\
\left\{c_{1} \rightarrow 0.32904814859405135+0.28045957195433746 \mathrm{i}\right\}
\end{array}\right\}
$$

Selecting the real value of $c_{1}$, i.e. $c_{1}=0.2762700280567808$; similarly other real values of $c_{1}$ with different values of $\in$ are presented in the Table 3.

Table 3. First order auxiliary constant of Case-2 for different values of $\in$

\begin{tabular}{ll}
\hline$\in$ & $c_{1}$ with $\mathrm{m}=0.3, s_{h}=4, \mathrm{G}=0.4, \alpha=1.4$ \\
\hline 0.2 & 0.27621397703119466 \\
0.4 & 0.2762325604405811 \\
0.6 & 0.27625124401164086 \\
0.8 & 0.2762700280567808 \\
\hline
\end{tabular}


Table 4. Results of Case-2 for different values of $\epsilon$

\begin{tabular}{|c|c|c|c|c|}
\hline $\mathrm{X}$ & $\epsilon=0.2$ & $\in=0.4$ & $\in=0.6$ & $\in=0.8$ \\
\hline 0 & 1 & 1 & 1 & 1 \\
\hline 0.1 & 0.9643597756885842 & 0.9642984524855956 & 0.964237124943611 & 0.9641757930335941 \\
\hline 0.2 & 0.9059448841587329 & 0.9057830512558182 & 0.9056212069022244 & 0.9054593510213241 \\
\hline 0.3 & 0.8340756269469365 & 0.8337901345235279 & 0.8335046218997645 & 0.8332190889404659 \\
\hline 0.4 & 0.7517870611975742 & 0.7513599816063354 & 0.7509328717965738 & 0.7505057315660677 \\
\hline 0.5 & 0.6607667330642797 & 0.6601830422797601 & 0.659599310195507 & 0.6590155365351437 \\
\hline 0.6 & 0.5621229543328996 & 0.5613695353105931 & 0.5606160629792303 & 0.5598625369820687 \\
\hline 0.7 & 0.4566524855151215 & 0.4557175921308103 & 0.45478263259700935 & 0.45384760647104794 \\
\hline 0.8 & 0.3449621273880217 & 0.34383505758968325 & 0.34270790804418494 & 0.34158067821786087 \\
\hline 0.9 & 0.22753298821876722 & 0.22620386775780854 & 0.22487465325335587 & 0.22354534407607263 \\
\hline 1 & 0.10475804136196842 & 0.10321767214673072 & 0.10167719394084285 & 0.10013660601494234 \\
\hline
\end{tabular}

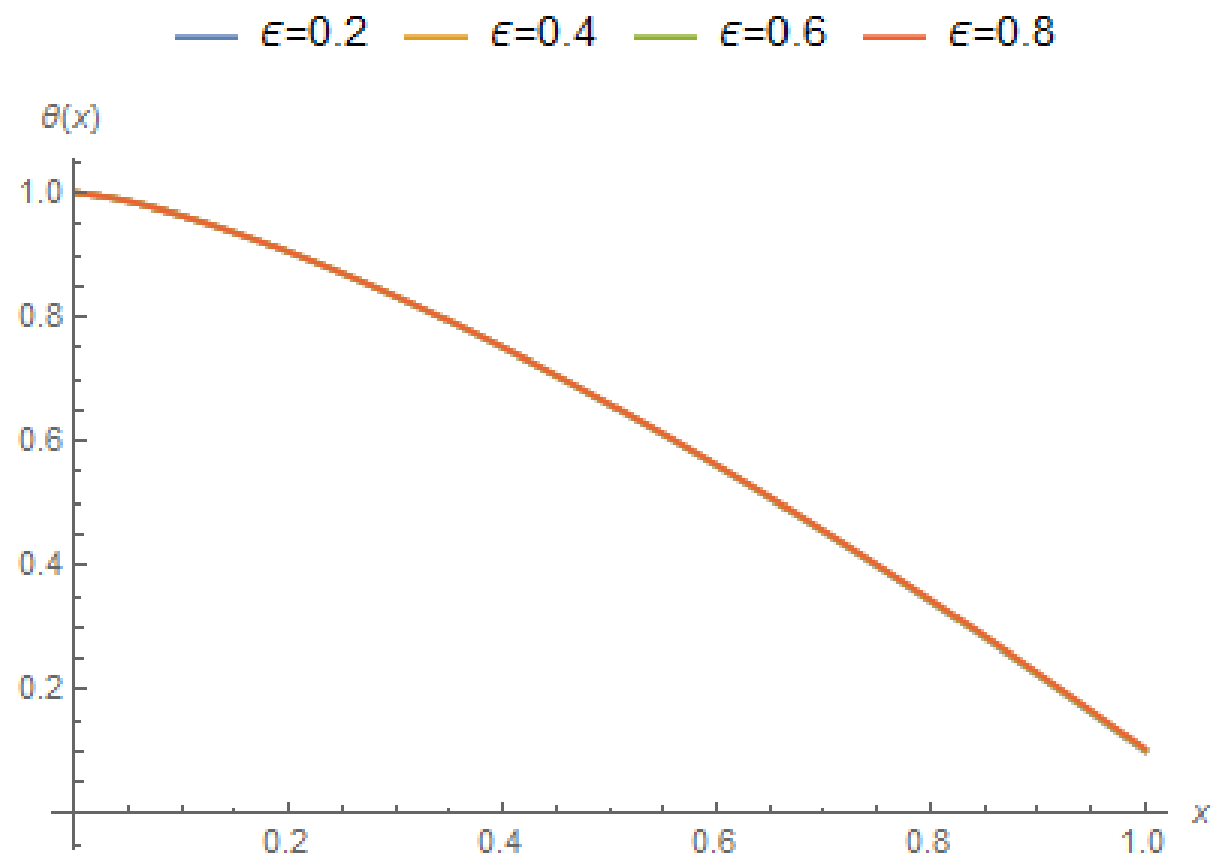

Fig 3. Temperature gradient for $2 \mathrm{D}$ Solutions of Case-2 with different values of

\section{Case-3 For Different Values of $G$}

In this case, fractional thermal analysis for variations in $G$ is given.

For $\mathrm{G}=0.8$

$$
\begin{aligned}
J= & 24.462915999999996-115.48377766946925 c_{1}+485.13063170384225 c_{1}^{2} \\
& -1009.82326407956 c_{1}^{3}+952.1147492340681 c_{1}^{4}
\end{aligned}
$$

After using the equation (28) we acquire the following $c_{1}$ values

$$
\left\{\begin{array}{l}
\left\{c_{1} \rightarrow 0.2645252692438751-0.2093993248771581 \mathrm{i}\right\} \\
\left\{c_{1} \rightarrow 0.2645252692438751+0.2093993248771581 \mathrm{l}\right\},\left\{c_{1} \rightarrow 0.26640762311402805\right\}
\end{array}\right\}
$$

Selecting the real value of $c_{1}, c_{1}=0.26640762311402805$, similarly other real values of $c_{1}$ with different values of $\mathrm{G}$ are presented in the Table 5. 
Table 5. First order auxiliary constant of Case- 3 for different values of

\begin{tabular}{ll}
\hline $\mathrm{G}$ & $c_{1}$ with $m=0.3, s_{h}=5, \in=0.6, \alpha=1.4$ \\
\hline 0.4 & 0.2643088748972952 \\
0.6 & 0.2652334985094893 \\
0.8 & 0.2661653446931716 \\
1 & 0.26640762311402805 \\
\hline
\end{tabular}

Table 6. Results of Case- 3 for different values of $\mathrm{G}$

\begin{tabular}{|c|c|c|c|c|}
\hline $\mathrm{X}$ & $\mathrm{G}=0.4$ & $\mathrm{G}=0.6$ & $\mathrm{G}=0.8$ & $\mathrm{G}=1$ \\
\hline 0 & 1 & 1 & 1 & 1 \\
\hline 0.1 & 0.9577701097529843 & 0.9575628385183665 & 0.9574665950851987 & 0.9573709069861848 \\
\hline 0.2 & 0.8885546514959832 & 0.8880076594284759 & 0.8877536714856259 & 0.8875011490783947 \\
\hline 0.3 & 0.8033971951997115 & 0.8024322363555874 & 0.8019841715182473 & 0.8015386920594542 \\
\hline 0.4 & 0.7058939620602154 & 0.7044504413398036 & 0.7037801631401407 & 0.7031137525121626 \\
\hline 0.5 & 0.598044515498646 & 0.596071651987834 & 0.595155581034706 & 0.594244795901826 \\
\hline 0.6 & 0.4811620875717604 & 0.47861554591497624 & 0.47743309572015746 & 0.47625746838022875 \\
\hline 0.7 & 0.3561907550807518 & 0.353030833606362 & 0.35156356926648746 & 0.3501047711873655 \\
\hline 0.8 & 0.2238495126647626 & 0.22004003864486654 & 0.2182711638711189 & 0.21651249568023845 \\
\hline 0.9 & 0.08470842265398071 & 0.08021602132018724 & 0.07813003901622739 & 0.07605609303703231 \\
\hline 1 & -0.06076688315617629 & -0.06597330117495948 & -0.06839082691392284 & -0.07079440328962172 \\
\hline
\end{tabular}

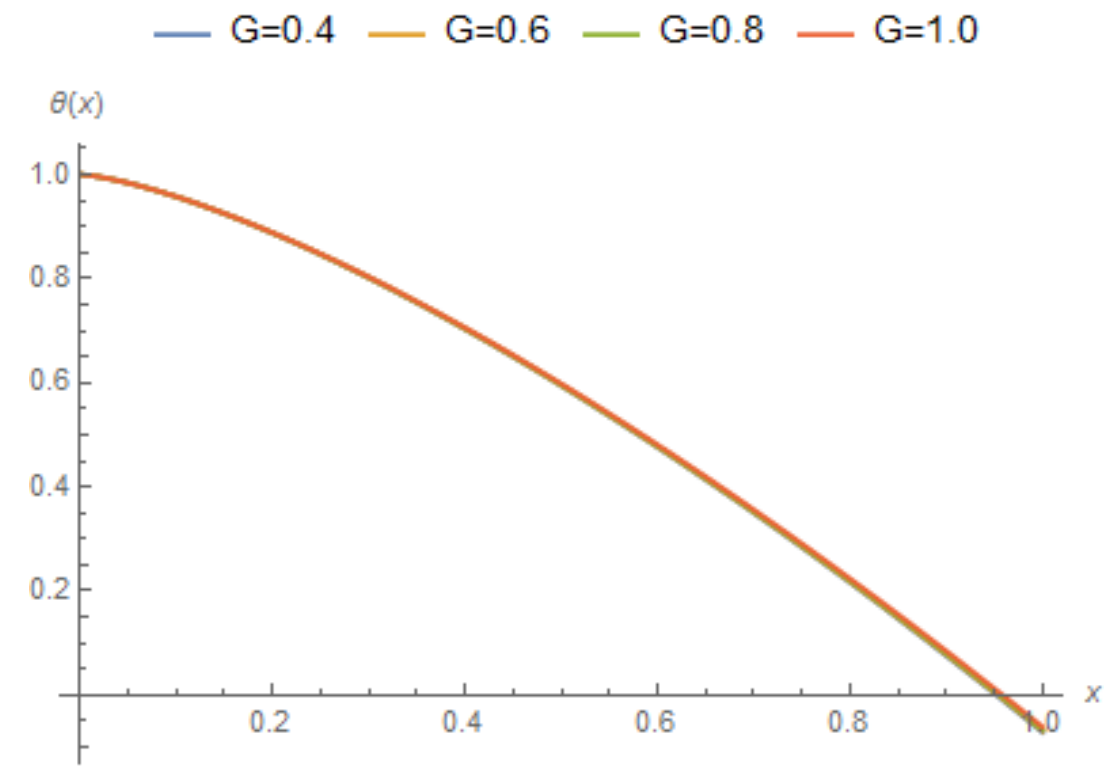

Fig 4. Temperature gradient for $2 \mathrm{D}$ Solutions of Case-3 with different values of $\mathrm{G}$

Case-4 For Different Values of $m$

In this case, fractional thermal analysis for variations in $\mathrm{m}$ is given.

For $m=0.4$

$$
\begin{aligned}
J= & 9.348917759999999-12.095797893387473 c_{1}+39.348436771384506 c_{1}^{2} \\
& -41.97306078934728 c_{1}^{3}+25.447520220624725 c_{1}^{4}
\end{aligned}
$$


After using the equation (28) we acquire the following $\mathrm{C}_{1}$ values

$$
\left\{\begin{array}{l}
\left\{c_{1} \rightarrow 0.21461118137176743\right\},\left\{c_{1} \rightarrow 0.5112182442317655-0.5407020467163509 \mathrm{i}\right\} \\
\left\{c_{1} \rightarrow 0.5112182442317655+0.5407020467163509 \mathrm{i}\right\}
\end{array}\right\}
$$

Selecting the real value of $c_{1}$, i.e. $c_{1}=0.21461118137176743$; similarly other real values of $c_{1}$ with different values of $m$ are presented in the Table 7.

Table 7. First order auxiliary constant of Case- 4 for different values of $m$

\begin{tabular}{ll}
\hline $\mathrm{m}$ & $c_{1}$ with $\mathrm{G}=0.4, S_{h}=3, \in=0.6, \alpha=1.6$ \\
\hline 0.1 & 0.20822199156438242 \\
0.2 & 0.20952219162255087 \\
0.3 & 0.21166422542123078 \\
0.4 & 0.21461118137176743 \\
\hline
\end{tabular}

Table 8. Results of Case- 4 for different values of $m$

\begin{tabular}{|c|c|c|c|c|}
\hline $\mathrm{X}$ & $\mathrm{m}=0.1$ & $\mathrm{~m}=0.2$ & $\mathrm{~m}=0.3$ & $\mathrm{~m}=0.4$ \\
\hline 0 & 1 & 1 & 1 & 1 \\
\hline 0.1 & 0.9884704856329178 & 0.9887225230142503 & 0.988902915086611 & 0.9890112905216663 \\
\hline 0.2 & 0.9650490481399878 & 0.965813082608519 & 0.9663599291136072 & 0.9666884619982394 \\
\hline 0.3 & 0.9331340495163218 & 0.9345957519370526 & 0.9356419440830593 & 0.9362704724185412 \\
\hline 0.4 & 0.8940485265009441 & 0.8963646459036193 & 0.8980223745178205 & 0.8990182999895816 \\
\hline 0.5 & 0.8485870497179298 & 0.8518969656670243 & 0.8542659896357703 & 0.8556892451032061 \\
\hline 0.6 & 0.79730034223285 & 0.8017313953816699 & 0.804902856916581 & 0.8068081985378031 \\
\hline 0.7 & 0.7406012500646381 & 0.7462717561738366 & 0.7503303380515083 & 0.7527686413036655 \\
\hline 0.8 & 0.6788151927425872 & 0.6858363538398891 & 0.6908616472865354 & 0.6938807287596512 \\
\hline 0.9 & 0.612207835322971 & 0.6206850459473411 & 0.6267524855639679 & 0.6303976646426208 \\
\hline 1 & 0.5410017657465018 & 0.551035554622101 & 0.558217092373878 & 0.5625315961546157 \\
\hline
\end{tabular}

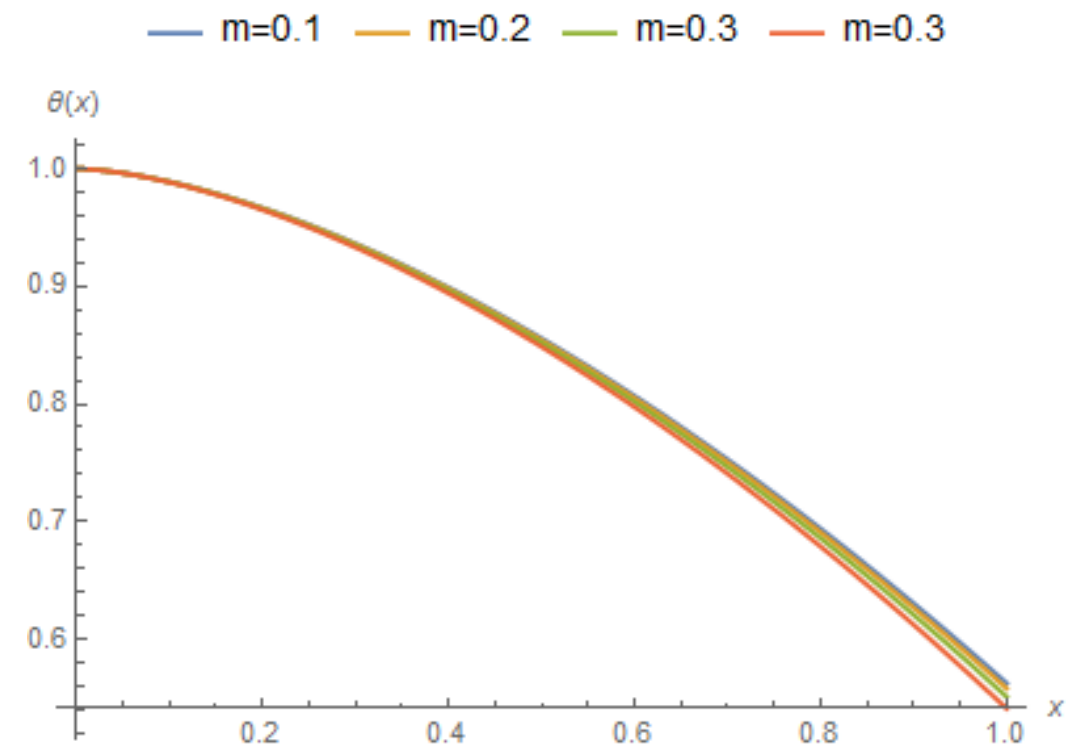

Fig 5. Temperature gradient for $2 \mathrm{D}$ Solutions of Case- 4 with different values of $\mathrm{m}$

\section{Case-5 For Different Values of $S$}


In this case, fractional thermal analysis for variations in $S$ is given.

For $S=5$

$$
\begin{aligned}
J= & 25.32504976-120.40999796972423 c_{1}+509.4759349185683 c_{1}^{2} \\
& -1070.1186964703948 c_{1}^{3}+1020.4070711435975 c_{1}^{4}
\end{aligned}
$$

After using the equation (28) we acquire the following $\mathrm{C}_{1}$ values

$$
\left\{\begin{array}{l}
\left\{c_{1} \rightarrow 0.2611146044119272-0.2084054318831474 i\right\} \\
\left\{c_{1} \rightarrow 0.2611146044119272+0.2084054318831474 i\right\},\left\{c_{1} \rightarrow 0.2643088748972952\right\}
\end{array}\right\}
$$

Selecting the real value of $c_{1}$, i.e. $c_{1}=0.2643088748972952$; similarly other real values of $c_{1}$ with different values of $s$ are presented in the Table 9.

Table 9. First order auxiliary constant of Case- 5 for different values of $S$

\begin{tabular}{ll}
\hline $\mathrm{S}_{h}$ & $c_{1}$ with $\mathrm{G}=0.4, \mathrm{~m}=0.3, \in=0.6, \alpha=1.4$ \\
\hline 2 & 0.17993772776777064 \\
3 & 0.26809839269109276 \\
4 & 0.27625124401164086 \\
5 & 0.2643088748972952 \\
\hline
\end{tabular}

Table 10. Results of Case-5 for different values of $S_{h}$

\begin{tabular}{lllll}
\hline $\mathrm{X}$ & $S_{h}=2$ & $S_{h}=3$ & $S_{h}=4$ & $S_{h}=5$ \\
\hline 0 & 1 & 1 & 1 & 1 \\
0.1 & 0.9573709069861848 & 0.9642984524855956 & 0.9739444712282638 & 0.9882793793142147 \\
0.2 & 0.8875011490783947 & 0.9057830512558182 & 0.9312390473326467 & 0.9690690965718759 \\
0.3 & 0.8015386920594542 & 0.8337901345235279 & 0.8786975289986707 & 0.94543421999567 \\
0.4 & 0.7031137525121626 & 0.7513599816063354 & 0.8185387580062936 & 0.9183728564784756 \\
0.5 & 0.594244795901826 & 0.6601830422797601 & 0.7519964501417977 & 0.8884399713365505 \\
0.6 & 0.47625746838022875 & 0.5613695353105931 & 0.6798808598348929 & 0.8560000432535864 \\
0.7 & 0.3501047711873655 & 0.4557175921308103 & 0.6027744754631792 & 0.8213150943665177 \\
0.8 & 0.21651249568023845 & 0.34383505758968325 & 0.5211209113812598 & 0.784584676779108 \\
0.9 & 0.07605609303703231 & 0.22620386775780854 & 0.43527189181477277 & 0.7459670074391239 \\
1 & -0.07079440328962172 & 0.10321767214673072 & 0.34551470812468443 & 0.7055913193050551 \\
\hline
\end{tabular}

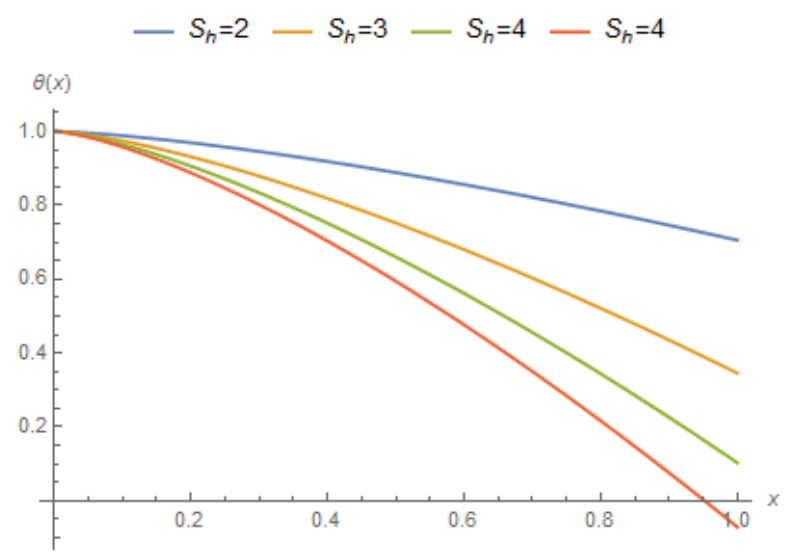

Fig 6. Temperature gradient for $2 \mathrm{D}$ Solutions of Case- 4 with different values of $S_{h}$ 
In the above, Figure 2 represents the thermal response behaviour of case- 1 for different values of $\alpha$, Figure 3 represents the internal heat behaviour of case- 2 for different values of $\in$, Figure 4 represents the generation numbers of case- 3 for different values of $\mathrm{G}$, Figure 5 represents the effect of surface convicting of the fin in case-4 for different values of $\mathrm{m}$, and Figure 6 represents the higher permeability of the porous medium in case- 5 for different values of $S_{h}$. All the above figures represent the accuracy, validity and effectiveness of the extended $\{\mathrm{OHAM}\}$ algorithm. It is cleared that as we proceed along the domain, we obtain consistent validity. All the tables also represent the strength of OHAM based solutions.

\section{Summary and Conclusions}

The above fractional thermal porous fin model, is a non-linear second-order ODE. In this work, the model solution is presented numerically by using the OHAM. It is presented that OHAM method offer unpretentious, correct and fitting method for forecasting heat dissipation effects in PFS with the occurrence of a thermionic system. We have two dissimilar types of cases subject to the tip situation of the fin, here the investigation of heat transfer is limited to porous fin of finite-length with insulated tip.

Figure 2 shows the thermal gradients that are outcome of consequence of dissimilarity of m on heat energy evolved and temperature propagation by varying values of $\alpha$. Figures 3 and 4 shows the thermal gradients that are outcome of consequence of dissimilarity of $\in$ and $G$ on heat energy evolved and temperature propagation by varying values respectively. It is concluded here that $S_{h}$ value rises, the temperature declines rapidly and the fin rapidly reaches the environmental temperature, as shown in Figure 5 as given in ${ }^{(19-24)}$, influenced by $m$. Figure 6 shows the thermal gradients are mainly influenced by $S_{h}$ and $S_{h}$ is mainly attributed to Darcy factor, and this factor is main cause of heat transfer rate in this thermal system. The results also explain the dissimilarity behavior due to porosity of fin and solidity of fin heat transfer rate with parameter $\mathrm{k}_{r}{ }^{(50-53)}$. Dissimilarity of proportion of porous fin to solid fin heat transfer rate rises as $\mathrm{k}_{r}$ upsurges for both the cases. The outcomes designate that the thermal dissemination of metallic $\mathrm{Cu}-\mathrm{Al}-\mathrm{Ag}$ porous structure is intensely conditional on the values and changes in $\mathrm{D}_{a}$ and $\mathrm{R}_{a}$. It is evident from that the scale of thermal gradients and thermionic levels is augmented with declining the Darcy parameter and accordingly clear from Figure 2, it is evident that the amount of dimensionless temperature reduces along the fin span. It is concluded here that $S_{h}$ parameter is mostly affecting the PFS, because the more the permeability, more convection and heat transferability in PFS is effective. Higher the $S_{h}$, more heat transfer is possible. This study leads to design of porous-finnedstructures (PFS) appropriate for several industrial applications, especially for use of electronics and bio-medical industry ${ }^{(33-37)}$

\section{Some Abbreviations and Nomenclature}

\begin{tabular}{ll}
\hline Constant & Description \\
\hline A & section area of fin \\
OHAM & Optimal Homotopy Asymptotic Method \\
$\mathrm{Cp}$ & Specific heat \\
$\mathrm{Ci}$ & Constants \\
$\mathrm{Da}$ & Darcy number \\
$\mathrm{G}$ & generation number, dimensionless \\
$\mathrm{H}$ & convection coefficient \\
$\mathrm{K}$ & thermal conductivity \\
$\mathrm{Kr}$ & thermal conductivity ratio [keff/kf] \\
$\mathrm{K}$ & Permeability \\
$\mathrm{L}$ & length of fin \\
$\mathrm{LS}$ & Least Square Method \\
$\mathrm{M}$ & convective parameter \\
$\mathrm{N}$ & number of iteration \\
$\mathrm{NUM}$ & Numerical Method \\
$\mathrm{Q}$ & conducted heat \\
$\mathrm{q}^{*}$ & internal heat generation \\
$\mathrm{R}(\mathrm{x})$ & residual function \\
$\mathrm{Ra}$ & Rayleigh number \\
$\mathrm{Sh}$ & porous parameter \\
$\mathrm{T}$ & Temperature \\
$\mathrm{Tb}$ & temperature at fin base \\
\hline
\end{tabular}

Continued on next page 
Table 11 continued

To sink temperature for convection

\section{References}

1) Saedodin S, Shahbabaei M. Thermal Analysis of Natural Convection in Porous Fins with Homotopy Perturbation Method (HPM). Arabian Journal for Science and Engineering. 2013;38(8):2227-2231. Available from: https://dx.doi.org/10.1007/s13369-013-0581-6.

2) Chakrabarti SS, Das PK, Ghosh I. Thermal behavior of wet porous and solid fin-Experimental and analytical approach. I J Mechanical Sciences. 2018;149:112-121.

3) Al-Srayyih BM, Gao S, Hussain SH. Effects of linearly heated left wall on natural convection within a superposed cavity filled with composite nanofluidporous layers. Advanced Powder Technology. 2019;30(1):55-72. Available from: https://dx.doi.org/10.1016/j.apt.2018.10.007.

4) Akbarzadeh P, Mahian O. The onset of Nano fluid natural convection inside a porous layer with rough boundaries. Journal of Molecular Liquids. 2018;272:344-352.

5) Joo Y, Kim J, S. Thermal optimization of vertically oriented, internally finned tubes in natural convection. International Journal of Heat and Mass Transfer. 2016;93:991-999.

6) Hatami M, Hasanpour A, Ganji D. Heat transfer study through porous fins (DOCXUPLOAD:INLINE:a3a9f7538e7a478989269b76dfa99894:ENDEQNBLOCK and DOCXUPLOAD:INLINE:ee8c7b681cf8494c92bd042a663937a0:ENDEQNBLOCK) with temperature-dependent heat generation. Energy Conversion and Management. 2013;74:9-16.

7) Ghasemi SE, Hatami H, Ganji DD. Thermal analysis of convective fin with temperature dependent thermal conductivity and heat generation. 2014.

8) Das. Estimation of parameters in a fin with temperature-dependent thermal conductivity and radiation. In: and others, editor. Proc Inst Mech Eng E J Process Mech Eng;vol. 230. 2016;p. 474-485.

9) Kiwan S, Al-Nimr MA. Using Porous Fins for Heat Transfer Enhancement. Journal of Heat Transfer. 2001;123(4):790-795. Available from: https: //dx.doi.org/10.1115/1.1371922.

10) Kiwan S. Thermal Analysis of Natural Convection Porous Fins. Transport in Porous Media. 2007;67(1):17-29. Available from: https://dx.doi.org/10.1007/ s11242-006-0010-3.

11) Khaled ARA. Investigation of Heat Transfer Enhancement Through Permeable Fins. Journal of Heat Transfer. 2010;132(3):132-132. Available from: https://dx.doi.org/10.1115/1.4000056.

12) Kiwan S, Zeitoun O. Natural convection in a horizontal cylindrical annulus using porous fins. International Journal of Numerical Methods for Heat \& Fluid Flow. 2008;18(5):618-634. Available from: https://dx.doi.org/10.1108/09615530810879747.

13) Sobamowo MG, Kamiyo OM, Adeleye OA. Thermal performance analysis of a natural convection porous fin with temperature-dependent thermal conductivity and internal heat generation. Thermal Science and Engineering Progress. 2017;1:39-52. Available from: https://dx.doi.org/10.1016/j.tsep. 2017.02.007.

14) Ghalambaz M, Jamesahar E, Ismael MA, Chamkha AJ. Fluid-structure interaction study of natural convection heat transfer over a flexible oscillating fin in a square cavity. International Journal of Thermal Sciences. 2017;111:256-273. Available from: https://dx.doi.org/10.1016/j.ijthermalsci.2016.09.001.

15) Cuce E, Cuce PM. A successful application of homotopy perturbation method for efficiency and effectiveness assessment of longitudinal porous fins. Energy Conversion and Management. 2015;93:92-99. Available from: https://dx.doi.org/10.1016/j.enconman.2015.01.003.

16) Ma J, Sun YS, Li BW, Chen H. Spectral collocation method for radiative- conductive porous fin with temperature dependent properties. Energy Convers Manage. 2016;111:279-288.

17) Moradi A, Fallah APM, Hayat T, Aldossary OM. On Solution of Natural Convection and Radiation Heat Transfer Problem in a Moving Porous Fin. Arabian Journal for Science and Engineering. 2014;39(2):1303-1312. Available from: https://dx.doi.org/10.1007/s13369-013-0708-9.

18) Bhanja D, Kundu B, Aziz A. Enhancement of heat transfer from a continuously moving porous fin exposed in convective-radiative environment. Energy Conversion and Management. 2014;88:842-853. Available from: https://dx.doi.org/10.1016/j.enconman.2014.09.016.

19) Hatami M, Ahangar GHRM, Ganji DD, Boubaker K. Refrigeration efficiency analysis for fully wet semi-spherical porous fins. Energy Conversion and Management. 2014;84:533-540. Available from: https://dx.doi.org/10.1016/j.enconman.2014.05.007.

20) Roy S, Schell KG, Bucharsky EC, Weidenmann KA, Wanner A, Hoffmann MJ. Processing and characterization of elastic and thermal expansion behaviour of interpenetrating Al12Si/alumina composites. Materials Science and Engineering: A. 2019;743:339-348. Available from: https://dx.doi.org/10.1016/j. msea.2018.11.100.

21) Sobamowo MG, Kamiyo OM, Adeleye OA. Thermal performance analysis of a natural convection porous fin with temperature-dependent thermal conductivity and internal heat generation. Thermal Science and Engineering Progress. 2017;1:39-52. Available from: https://dx.doi.org/10.1016/j.tsep. 2017.02.007.

22) Yasong JM, Lic S. Simulation of combined conductive, convective and radiative heat transfer in moving irregular porous fins by spectral element method. IJ of Thermal Sciences. 2017;118:475-487.

23) Hirata $Y$, Kinoshita $Y$, Shimonosono T, Chaen T. Theoretical and experimental analyses of thermal properties of porous polycrystalline mullite. Ceramics International. 2017;43(13):9973-9978. Available from: https://dx.doi.org/10.1016/j.ceramint.2017.05.009.

24) Ouyang XL, Xu RN, Jiang PX. Three-equation local thermal non-equilibrium model for transient heat transfer in porous media: The internal thermal conduction effect in the solid phase. International Journal of Heat and Mass Transfer. 2017;115:1113-1124. Available from: https://dx.doi.org/10.1016/j. ijheatmasstransfer.2017.07.088.

25) Wang L, Zeng Z, Zhang L, Xie H, Lu Y. A lattice Boltzmann model for thermal flows through porous media. Applied Thermal Engineering. 2016;108:66-75.

26) Tang GH, Bi C, Zhao Y, Tao WQ. Thermal transport in nano-porous insulation of aerogel: Factors, models and outlook. Energy. 2015;90:701-721. Available from: https://dx.doi.org/10.1016/j.energy.2015.07.109.

27) Ozgumus T, Mobedi M. Effect of pore to throat size ratio on thermal dispersion in porous media. International Journal of Thermal Sciences. 2016;104:135145. Available from: https://dx.doi.org/10.1016/j.ijthermalsci.2016.01.003.

28) Jin X, Dong L, Li Q, Tang H, Qu Q. Thermal shock cracking of porous ZrB2-SiC ceramics. Ceramics International. 2016;42(11):13309-13313.

29) Marinca V, Herisanu N. The optimal homotopy asymptotic method for solving Blasius equation. Appl Maths Comput. 2014;231:134-139. 
30) Ali L, Tassaddiq A, Ali R, Islam S, Gul T, Kumam P, et al. A new analytical approach for the research of thin-film flow of magneto hydrodynamic fluid in the presence of thermal conductivity and variable viscosity. ZAMM - Journal of Applied Mathematics and Mechanics / Zeitschrift für Angewandte Mathematik und Mechanik. 2021;101(2). Available from: https://dx.doi.org/10.1002/zamm.201900292.

31) Esfe MH, Bahiraei M, Hajbarati H, Valadkhani M. A comprehensive review on convective heat transfer of nanofluids in porous media: Energy-related and thermohydraulic characteristics. Applied Thermal Engineering. 2020;178. Available from: https://dx.doi.org/10.1016/j.applthermaleng.2020.115487.

32) Ndlovu PL, Moitsheki RJ. Steady state heat transfer analysis in a rectangular moving porous fin. Propulsion and Power Research. 2020;9:188-196. Available from: https://dx.doi.org/10.1016/j.jppr.2020.03.002.

33) Shah Z, Bonyah E, Islam S, Gul T. Impact of thermal radiation on electrical MHD rotating flow of Carbon nanotubes over a stretching sheet. AIP Advances. 2019;9(1). Available from: https://dx.doi.org/10.1063/1.5048078.

34) Shah Z, Dawar A, Islam S, Khan I, Ching C. Darcy-Forchheimer Flow of Radiative Carbon Nanotubes with Microstructure and Inertial Characteristics in the Rotating Frame. 2019.

35) Shah Z, Dawar A, Alzahrani EO, Kumam P, Khan AJ, Islam S. Hall Effect on Couple Stress 3D Nanofluid Flow Over an Exponentially Stretched Surface With Cattaneo Christov Heat Flux Model. IEEE Access. 2019;7:64844-64855. Available from: https://dx.doi.org/10.1109/access.2019.2916162.

36) Nasir S, Shah Z, Islam S, Khan W, Khan SN. Radiative flow of magneto hydrodynamics single-walled carbon nanotube over a convectively heated stretchable rotating disk with velocity slip effect. Advances in Mechanical Engineering. 2019;11(3). Available from: https://dx.doi.org/10.1177/ 1687814019827713.

37) Nasir S, Shah Z, Islam S, Bonyah E, Gul T. Darcy Forchheimer nanofluid thin film flow of SWCNTs and heat transfer analysis over an unsteady stretching sheet. AIP Advances. 2019;9(1). Available from: https://dx.doi.org/10.1063/1.5083972.

38) Shah Z, Dawar A, Kumam P, Khan W, Islam S. Impact of Nonlinear Thermal Radiation on MHD Nanofluid Thin Film Flow over a Horizontally Rotating Disk. Applied Sciences. 2019;9(8). Available from: https://dx.doi.org/10.3390/app9081533.

39) Shah Z, Islam S, Ayaz H, Khan S. Radiative Heat and Mass Transfer Analysis of Micropolar Nanofluid Flow of Casson Fluid Between Two Rotating Parallel Plates With Effects of Hall Current. Journal of Heat Transfer. 2019;141(2). Available from: https://dx.doi.org/10.1115/1.4040415.

40) Sheikholeslami M, Shah Z, Shafee A, Khan I, Tlili I. Uniform magnetic force impact on water based nanofluid thermal behavior in a porous enclosure with ellipse shaped obstacle. Scientific Reports. 2019;9(1):1196-1196. Available from: https://dx.doi.org/10.1038/s41598-018-37964-y.

41) Sheikholeslami M, Shah Z, Tassaddiq A, Shafee A, Khan I. Application of Electric Field for Augmentation of Ferrofluid Heat Transfer in an Enclosure Including Double Moving Walls. IEEE Access. 2019;7:21048-21056. Available from: https://dx.doi.org/10.1109/access.2019.2896206.

42) Shah Z, Islam S, Gul T, Bonyah E, Khan MA. The electrical MHD and Hall current impact on micropolar nanofluid flow between rotating parallel plates. Results in Physics. 2018;9:1201-1214. Available from: https://dx.doi.org/10.1016/j.rinp.2018.01.064.

43) Kumar R, Kumar R, Shehzad SA, Chamkha AJ. Optimal treatment of stratified Carreau and Casson nanofluids flows in Darcy-Forchheimer porous space over porous matrix. Applied Mathematics and Mechanics. 2020;41(11):1651-1670. Available from: https://dx.doi.org/10.1007/s10483-020-2655-7.

44) Nawaz R, Hussain Z, Khattak A, Khan A. Extension of Optimal Homotopy Asymptotic Method with Use of Daftardar-Jeffery Polynomials to Coupled Nonlinear-Korteweg-De-Vries System. Complexity. 2020;2020:1-6. Available from: https://dx.doi.org/10.1155/2020/6952709.

45) Iqbal S, Idrees M, Siddiqui AM, Ansari AR. Some solutions of the linear and nonlinear Klein-Gordon equations using the optimal homotopy asymptotic method. Applied Mathematics and Computation. 2010;216(10):2898-2909. Available from: https://dx.doi.org/10.1016/j.amc.2010.04.001.

46) Iqbal S, Javed A. Application of optimal homotopy asymptotic method for the analytic solution of singular Lane-Emden type equation. Applied Mathematics and Computation. 2011;217(19):7753-7761. Available from: https://dx.doi.org/10.1016/j.amc.2011.02.083.

47) Hashmi MS, Khan N, Iqbal S. Numerical solutions of weakly singular Volterra integral equations using the optimal homotopy asymptotic method. Computers \& Mathematics with Applications. 2012;64(6):1567-1574. Available from: https://dx.doi.org/10.1016/j.camwa.2011.12.084.

48) Hashmi MS, Khan N, Iqbal S. Optimal homotopy asymptotic method for solving nonlinear Fredholm integral equations of second kind. Applied Mathematics and Computation. 2012;218(22):10982-10989. Available from: https://dx.doi.org/10.1016/j.amc.2012.04.059.

49) Javed A, Iqbal S, Hashmi MS, Amir HD, Khan N. Semi analytical solutions of non-linear problems of deformation beams and plate detection theory using optimal homotopy asymptotic method. Heat Transfer Res. 2014. Available from: http://dx.doi.org/10.1615/HeatTransRes.2014007084.

50) Golbabai A, Fardi M, Sayevand K. Application of the optimal homotopy asymptotic method for solving a strongly nonlinear oscillatory system. Mathematical and Computer Modelling. 2013;58(11-12):1837-1843. Available from: https://dx.doi.org/10.1016/j.mcm.2011.12.027.

51) Pankaj S, Santosh B, Kishor K, Sarang J. Experimental Investigation of Heat Transfer by Natural Convection with Perforated Pin Fin Array. Procedia Manufacturing. 2018;20:311-317. Available from: https://dx.doi.org/10.1016/j.promfg.2018.02.046.

52) Tijani AS, Jaffri NB. Thermal analysis of perforated pin-fins heat sink under forced convection condition. Procedia Manufacturing. 2018;24:290-298. Available from: https://dx.doi.org/10.1016/j.promfg.2018.06.025.

53) Kwon H, Joo Y, Kim SJ. Analytic approach to thermal optimization of horizontally oriented radial plate-fin heat sinks in natural convection. Energy Conversion and Management. 2018;156:555-567. Available from: https://dx.doi.org/10.1016/j.enconman.2017.11.076. 